\title{
ARTHUR SCHOPENHAUER NO BRASIL (1887-2015)
}

\section{ARTHUR SCHOPENHAUER IN BRAZIL (1887-2015)}

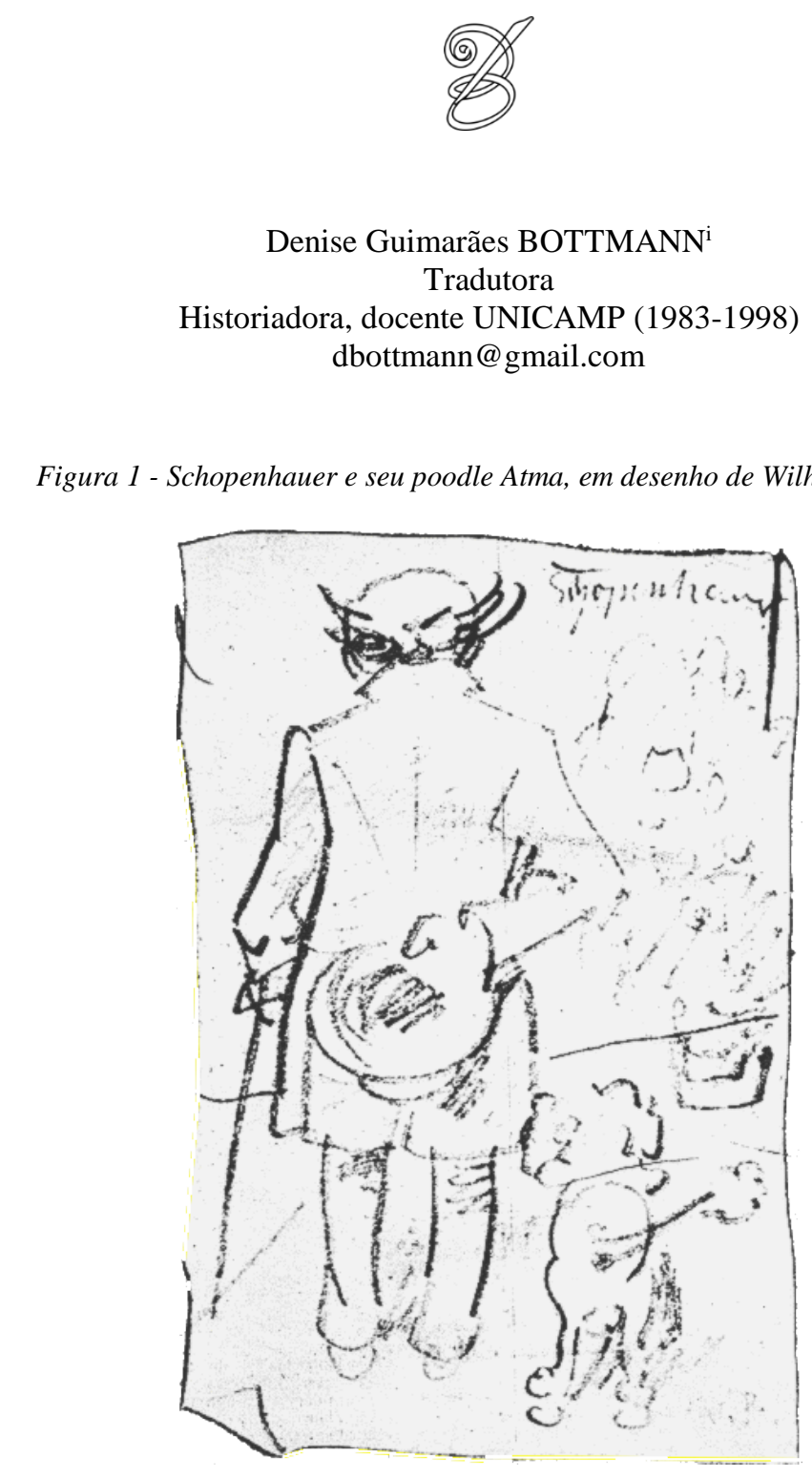

\section{Inícios}

chopenhauer chega ao Brasil em 1887, com Pensamentos e fragmentos: Metaphysica do amor. Esboço sobre as mulheres, pela Laemmert, em tradução de Manuel Coelho da Rocha. [Rio de Janeiro: Laemmert, 1887. 72 p.]

Manuel Coelho da Rocha muito provavelmente adotou como texto de base a tradução francesa de Jean Bourdeau, Pensées et fragments (1880). Em 1904, a Laemmert, em sua 
Bibliotheca Philosophica, lança a quarta edição da obra em português, agora "augmentada com um appendice sobre a pederastia", conforme especifica sua nova capa. O volume agora sai com 99 p. A obra foi reeditada pela editora paulista Cultura Moderna em 1938.

Transcorrem quase 45 anos antes que tenhamos novos lançamentos.

\section{Anos 1930}

Em 1931, a carioca Livraria H. Antunes publica Dores do mundo - A metafísica do amor - A morte - A arte - A moral - O homem e a sociedade, sem créditos de tradução, muito possivelmente retomando a tradução lusitana de Albino Forjaz de Sampaio (1913).

Com toda probabilidade, é essa mesma edição que será relançada, agora como "tradução revista por José Sousa de Oliveira", pela Edições e Publicações Brasil em 1944 e pela Edigraf, sem data, em sua Biblioteca de Autores Célebres. Reed. Edições de Ouro, 1979; Edipro, 2013, porém como "tradução de José Sousa de Oliveira".

Entre 1936 e 1939, além de reeditar a tradução de Manuel Coelho da Rocha para $A$ metafísica do amor (em 1938), a Cultura Moderna publica dois novos títulos em sua coleção

252 As Grandes Obras, vols. 9 e 39, a saber: O amor, as mulheres e a morte, com tradução de Emilio Paraizo, em 1936 (266 p.), e, mais importante, A sabedoria da vida, com tradução direta do alemão, introdução e notas de Rômulo Argentière, aquele se tornaria importante e afamado físico nuclear, então ainda muito jovem. São interessantes suas considerações no prefácio sobre a importância de Schopenhauer não só para a psicanálise, mas também para a teoria da relatividade. O livro sai em 1939, com 272 p. Reed. Edipro, 2012 (trazendo Argentière grafado como Argetière)

\section{Anos 1940}

A década de 1940 é um pouco mais profícua para a schopenhaueriana brasileira.

Em 1941, temos três lançamentos. A Edições e Publicações Brasil traz O mundo como vontade e representação, em tradução e prefácio de Heraldo Barbuy (238p.), em sua coleção As Grandes Obras da Filosofia, com várias reedições. Sai também pelas Edições de Ouro, 1966 em diante.

A Martins publica $O$ pensamento vivo de Schopenhauer, em apresentação de Thomas Mann, com tradução de Pedro Ferraz do Amaral. São Paulo: Livraria Martins, 1941. 230p.

E no mesmo ano temos ainda $O$ amor, as mulheres e a morte, em tradução de Persiano da Fonseca. Série Os Grandes Pensadores. Rio de Janeiro: Ed. Vecchi, 1941. 119p. 
Alguns anos depois, temos $O$ livre arbítrio, em tradução de Lohengrin de Oliveira e com prefácio de Afonso Bertagnoli. Biblioteca de Autores Célebres, 1. São Paulo: Ed. e Publ. Brasil, 1944 (2a. ed.). 171p. Será reeditado pela Edições de Ouro, 1967; Saraiva, Col. Clássicos de Bolso, 2012.

Por fim temos Regras de conduta para bem viver (Eudemonologia), com tradução de Eloy Pontes. Rio de Janeiro: Vecchi, 1946. 195 p.

\section{Anos 1950}

Em 1951, surge um lançamento muito interessante. Trata-se de $O$ instinto sexual, com tradução direta do alemão por Hans Koranyi, acompanhado de uma introdução por Anatol H. Rosenfeld. São Paulo: Inedos, 1951.98 p. Reed. O Livreiro, sem créditos, em 1963, com 110 p.

Ainda que Rômulo Argentiére já houvesse, nos anos 1930, destacado a importância de Schopenhauer para a psicanálise, a edição da Inedos é a única que enfoca o filósofo pelo lado especificamente psicanalítico. Veja-se abaixo, na galeria de imagens, uma pequena curiosidade: o anúncio que a Inedos publicou no jornal Correio da Manhã, de 4 de julho de 1954.

Ainda em 1951, temos uma nova tradução de Dores do mundo, agora por A.F. Rocha. Coleção Livros de Ontem e de Hoje, vol. 2. Rio de Janeiro: Organização Simões, 1951. 174 p.

Na década de 1950, saem também:

1. Aforismos para a sabedoria na vida. Tradução de e prefácio por Genésio de Almeida Moura. São Paulo: Melhoramentos, 1953. 232p.

2. Dores do mundo - A metafísica do amor, a morte, a arte, a moral, o homem e a sociedade. Coleção Temas do Nosso Tempo. Salvador: Livraria Progresso, 1957. 205p.

Provavelmente retoma a mesma tradução portuguesa que aventei acima como fonte para a edição da H. Antunes, de 1931.

“O estoicismo", in O pensamento de Epicteto. Tradução de Hans Koranyi. Coleção A Sabedoria do Mundo. São Paulo: Iris, 1959. 


\section{Anos 1960}

Entre a década de 1960 e a de 1980, parece ter diminuído um pouco o interesse editorial na divulgação do pensamento de Schopenhauer entre nós. Para os anos 1960 temos apenas dois lançamentos:

1. A necessidade metafísica. Tradução de Artur Versiani Velloso. Belo Horizonte: Itatiaia, 1960. 153 p.

2. A vontade de amar. Tradução de Aurélio de Oliveira. Prefácio de Torrieri Guimarães. São Paulo: Edimax, c. 1964. 136 p. Reed. Edições de Ouro, 1966; Hemus/ Leopardo, 2010.

\section{Anos 1970}

Embora essa década também seja escassa, aqui temos uma edição que foi um marco na schopenhaueriana brasileira, apresentando ao amplo público leitor uma coletânea de rigor acadêmico, com diversas reedições. Trata-se do volume XXXI d'Os Pensadores, contendo $O$

254 mundo como vontade e representação (parte III); Crítica da filosofia kantiana; Parerga e paralipomena (capítulos V, VIII, XII e XIV). Tradução de Maria Lúcia Cacciola e Wolfgang Leo Maar. Coleção Os Pensadores, vol. XXXI. São Paulo: Abril Cultural, 1974.

Em 1978, a editora Formar lança $O$ livre-arbítrio em conjunto com $O$ elogio da loucura, de Erasmo de Rotterdam, em sua coleção Grandes Mestres do Pensamento. Não localizei créditos de tradução. A grafia "Artur" e "Roterdã" parece sugerir que se trata de uma tradução portuguesa.

\section{Anos 1980}

Para essa década, localizei apenas duas publicações de $O$ livre-arbítrio, também em conjunto com O elogio da loucura, tal como o volume publicado em 1978 pela Formar. Saíram pela Novo Horizonte, na coleção Os Grandes Clássicos da Literatura III, em 1982, e pela Nova Brasil, na coleção Os Maiores Clássicos de Todos os Tempos, em 1986. A respeito delas aplica-se o mesmo que disse sobre a edição da Formar: não há créditos de tradução e a grafia "Artur" e "Roterdã" parece sugerir que se trata de uma tradução portuguesa. 


\section{Anos 1990}

1. Aforismos sobre filosofia de vida. Tradução de Gilza Martins Saldanha da Gama. Rio de Janeiro: Ediouro, 1991.

2. Sobre a filosofia universitária. Tradução, apresentação e notas de Maria Lucia Cacciola e Marcio Suzuki. São Paulo: Polis, 1991. Reed. Martins Fontes, 2001.

3. Sobre livros e leitura $=$ : Uber Lesen und Bucher. Tradução de Philippe Humble e Walter Carlos Costa. Florianópolis: Paraula, 1993. Edição bilíngue.

4. Fragmentos para a história da filosofia. Tradução, apresentação e notas de Maria Lúcia Cacciola. Biblioteca Pólen. São Paulo: Iluminuras, 1995.

5. Sobre o fundamento da moral. Tradução de Maria Lucia Cacciola. Coleção Clássicos. São Paulo: Martins Fontes, 1995.

6. Como vencer um debate sem precisar ter razão. Tradução de Daniela Caldas e Olavo de Carvalho. Rio de Janeiro: Topbooks, 1997.

\section{Anos 2000}

A partir de 2000, tem-se um trabalho mais constante e sistemático de tradução da obra de Schopenhauer, com destaque para os lançamentos da WMF Martins Fontes e de editoras universitárias.

1. Metafísica do amor, metafísica da morte. Tradução de Jair Barboza. Coleção Obras de Schopenhauer. São Paulo: Martins Fontes, 2000.

2. A metafísica do belo. Tradução, apresentação e notas de Jair Barboza. São Paulo: Unesp, 2001.

3. O mundo como vontade e representação. Tradução de M. F. Sá Correia. Rio de Janeiro: Contraponto, 2001.

4. A arte de ser feliz: exposta em 50 máximas. Organização e ensaio de Franco Volpi; tradução de Marion Fleischer (alemão) e Eduardo Brandão (italiano). São Paulo: Martins Fontes, 2001.

5. A arte de ter razão: exposta em 38 estratagemas. Organização e ensaio de Franco Volpi; Tradução de Alexandre Krug (alemão) e Eduardo Brandão (italiano). São Paulo: WMF Martins Fontes, 2001.

6. Aforismos para a sabedoria de vida. Tradução de Jair Barboza. Coleção Obras de Schopenhauer. São Paulo: Martins Fontes, 2002. Reed. Coleção Folha Grandes Nomes do Pensamento, 2015.

7. Sobre a visão e as cores. Tradução de Erlon José Paschoal. São Paulo: Nova Alexandria, 2003. 
8. Sobre o ofício do escritor. Tradução de Luiz Sérgio Repa (alemão) e Eduardo Brandão (italiano). Série Breves Encontros. São Paulo: Martins Fontes, 2003.

9. A arte de se fazer respeitar exposta em 14 máximas, ou, Tratado sobre a honra. Organização e ensaio de Franco Volpi; Tradução de Maria Lúcia Mello Oliveira Cacciola (alemão) e Karina Jannini (italiano). São Paulo: Martins Fontes, 2003.

10. A arte de insultar. Organização e ensaio de Franco Volpi; Tradução de Karina Jannini (alemão) e Eduardo Brandão (italiano). São Paulo: Martins Fontes, 2003.

11. A arte de lidar com as mulheres. Organização e ensaio de Franco Volpi; tradução de Eurides Avance de Souza (alemão) e Karina Jannini (italiano). São Paulo: Martins Fontes, 2004.

12. $O$ mundo como vontade e como representação: primeiro tomo. Tradução, apresentação, notas e índices de Jair Barboza. São Paulo: Ed. UNESP, 2005.

13. A arte de escrever. Organização, tradução, prefácio e notas de Pedro Süssekind. Porto Alegre: L\&amp;PM, 2005.

14. O amor: receitas práticas e sábias. Nietzsche, Schopenhauer, Ovídio, Platão e outros. Tradução de Renata Cordeiro. São Paulo: Landy, 2006.

15. Fragmentos sobre a história da filosofia [precedido de Esboço de uma história da doutrina do ideal e do real]. Tradução de Karina Jannini, prefácio de Jair Barboza. São Paulo: Martins Fontes, 2007.

16. A sabedoria da vida - A arte de organizar a vida e ter prazer e sucesso (excertos de Parerga e paralipomena). Tradução de Jeanne Rangel. São Paulo: Golden Books, 2007.

17. A arte de conhecer a si mesmo. Organização e ensaio de Franco Volpi; tradução de Jair Barboza (alemão) e Silvana Cobucci Leite (italiano). São Paulo: WMF Martins Fontes, 2009.

18. "Sobre o suicídio", in Os filósofos e o suicídio. Organização da coletânea e tradução de deste artigo por Fernando Rey Puente. Belo Horizonte: UFMG, 2008.

\section{Anos 2010}

1. Sobre a filosofia e seu método. (Excerto de Parerga e paralipomena). Tradução de Flamarion Caldeira Ramos. São Paulo: Hedra, 2010.

2. Sobre a ética (Excerto de Parerga e paralipomena). Tradução de Flamarion Caldeira Ramos. São Paulo: Hedra, 2012.

3. Bastar a si mesmo. Tradução de Jair Barboza. São Paulo: WMF Martins Fontes, 2012. 
4. A arte de envelhecer, ou, Senilia/ baseado na transcrição de Ernst Ziegler. Organização e introdução de Franco Volpi; tradução de Karina Jannini. São Paulo: WMF Martins Fontes, 2012.

5. Sobre a morte: pensamentos e conclusões sobre as últimas coisas. Organização de Ernst Ziegler e Franco Volpi; tradução de Karina Jannini. São Paulo: WMF Martins Fontes, 2013.

6. Aforismos para a sabedoria de vida. Tradução de Gabriel Valladão Silva. Porto Alegre: L\&PM, 2014.

7. Sobre a vontade na natureza. Tradução, prefácio e notas de Gabriel Valladão Silva. Porto Alegre: L\&PM, 2014.

8. 38 estratégias para vencer qualquer debate: a arte de ter razão. Tradução de Camila Werner. São Paulo: Faro, 2014.

9. O mundo como vontade e representação. Volume 1 (Tomo II, Complementos Livros I-II). Tradução de Eduardo Ribeiro da Fonseca. Curitiba: Editora da UFPR, 2014.

10. O mundo como vontade e representação. Volume 2 (Tomo II, Complementos Livros III-IV). Tradução de Eduardo Ribeiro da Fonseca. Curitiba: Editora da UFPR, 2014.

11. O mundo como vontade e como representação: segundo tomo. Tradução, apresentação, notas e índices Jair Barboza. São Paulo: Ed. UNESP, 2015.

Para finalizar, fique registrada a edição espúria lançada pela Martin Claret: Da Morte, Metafísica do Amor, Do Sofrimento do Mundo, com tradução atribuída a Pietro Nassetti. São Paulo: Martin Claret, 2001, em sucessivas reedições até a presente data.

Segue-se uma pequena galeria com algumas imagens de capa de edições antigas e anúncios em jornais da época:

Figura 2 - A Semana, 1887, ed. 0144

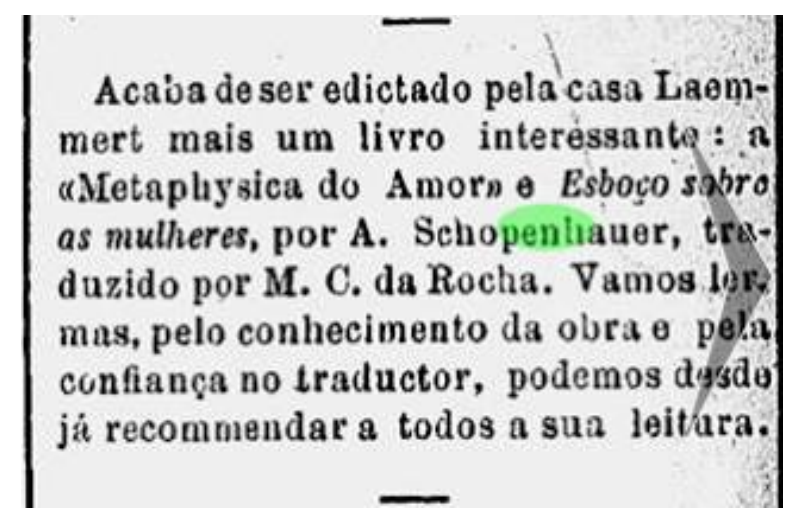


Figura 3 - Laemmert, 1904 (4ª . ed.)

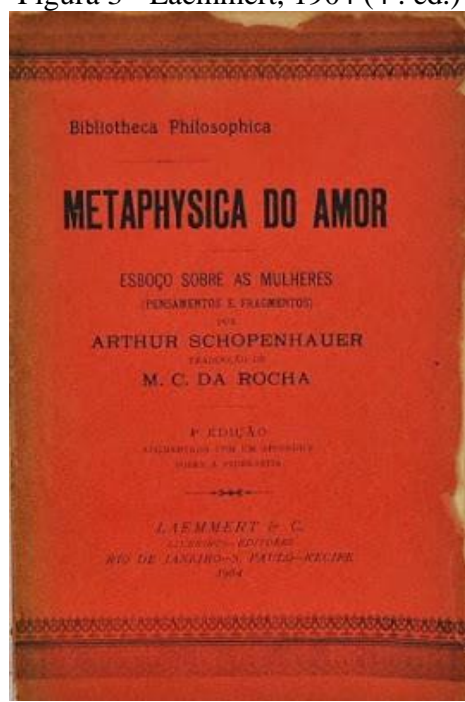

Figura 4 - H. Antunes, 1931

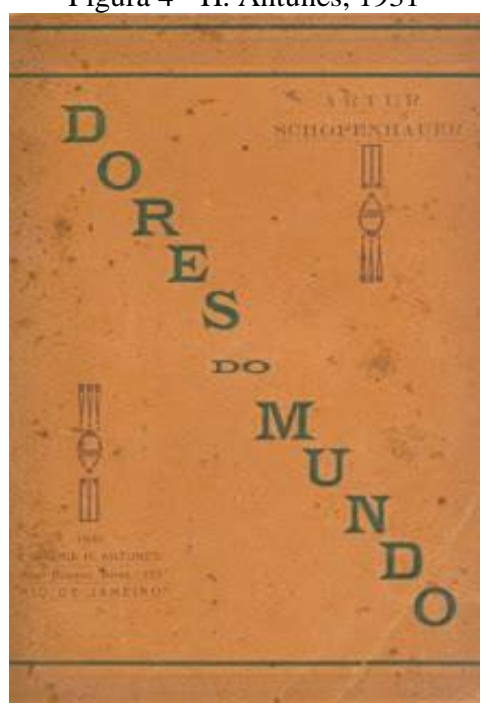

Figura 5 - Cultura Moderna, 1939

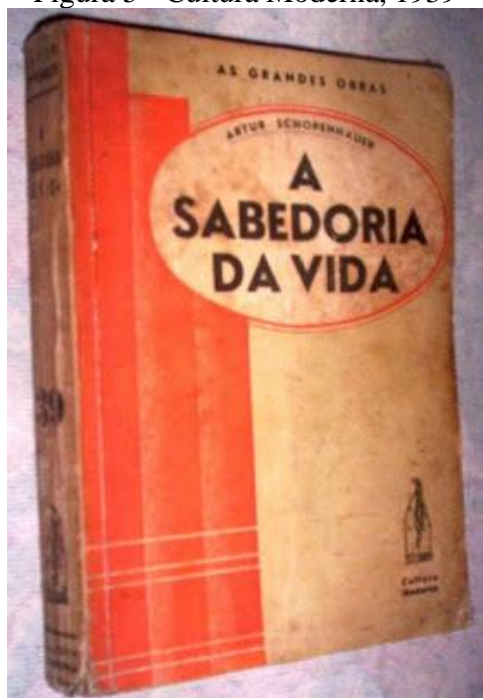




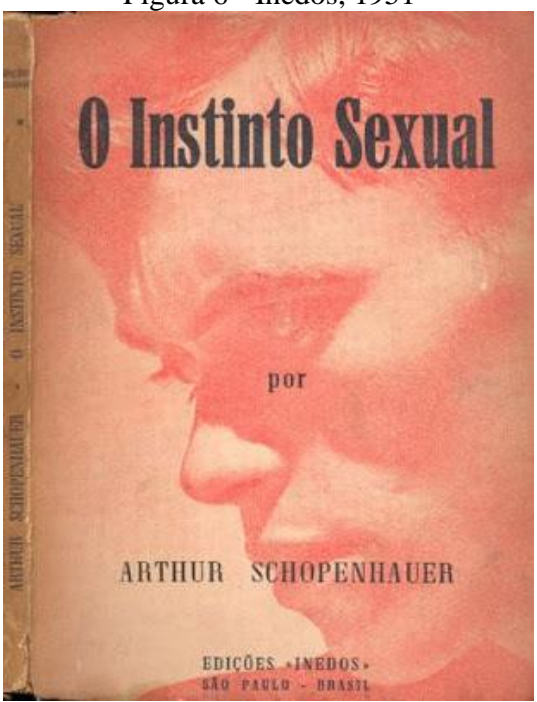

Figura 7 - Correio da Manhã, 4 de julho de 1954

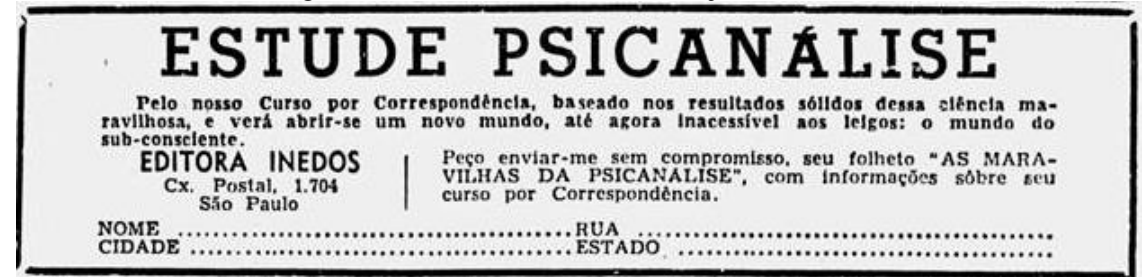

\section{FONTES}

Fundação Biblioteca Nacional, Hemeroteca Digital da FBN

Sociedade Schopenhauer do Brasil, Bibliografia Filosófica Brasileira 1808/1985

Periódicos acadêmicos

Sebos virtuais

Google Images

i Denise BOTTMANN - Mestre em História pela Universidade Estadual de Campinas (1985). Graduada em História pela Universidade Federal do Paraná (1981). Disponível em: http://lattes.cnpq.br/4979718236781288. Acesso: junho de 2016.

RECEBIDO EM: 28 de maio de 2016

ACEITO EM: 06 de junho de 2016 